\title{
Cost-effectiveness of available treatment options for patients suffering from severe COPD in the UK: a fully incremental analysis
}

This article was published in the following Dove Press journal: International Journal of COPD

16 March 2012

Number of times this article has been viewed

\author{
Nadine Hertel' \\ Robert W Kotchie' \\ Yevgeniy Samyshkin' \\ Matthew Radford' \\ Samantha Humphreys ${ }^{2}$ \\ Kevin Jameson ${ }^{2}$ \\ 'IMS Consulting Group, London, UK; \\ ${ }^{2}$ MSD Ltd, Hoddesdon, UK
}

\begin{abstract}
Purpose: Frequent exacerbations which are both costly and potentially life-threatening are a major concern to patients with chronic obstructive pulmonary disease (COPD), despite the availability of several treatment options. This study aimed to assess the lifetime costs and outcomes associated with alternative treatment regimens for patients with severe COPD in the UK setting.
\end{abstract}

Patients and methods: A Markov cohort model was developed to predict lifetime costs, outcomes, and cost-effectiveness of various combinations of a long-acting muscarinic antagonist (LAMA), a long-acting beta agonist (LABA), an inhaled corticosteroid (ICS), and roflumilast in a fully incremental analysis. Patients willing and able to take ICS, and those refusing or intolerant to ICS were analyzed separately. Efficacy was expressed as relative rate ratios of COPD exacerbation associated with alternative treatment regimens, taken from a mixed treatment comparison. The analysis was conducted from the UK National Health Service (NHS) perspective. Parameter uncertainty was explored using one-way and probabilistic sensitivity analysis.

Results: Based on the results of the fully incremental analysis a cost-effectiveness frontier was determined, indicating those treatment regimens which represent the most cost-effective use of NHS resources. For ICS-tolerant patients the cost-effectiveness frontier suggested LAMA as initial treatment. Where patients continue to exacerbate and additional therapy is required, LAMA + LABA/ICS can be a cost-effective option, followed by LAMA + LABA/ ICS + roflumilast (incremental cost-effectiveness ratio [ICER] versus LAMA + LABA/ICS: $£ 16,566$ per quality-adjusted life-year [QALY] gained). The ICER in ICS-intolerant patients, comparing LAMA + LABA + roflumilast versus LAMA + LABA, was £13,764/QALY gained. The relative rate ratio of exacerbations was identified as the primary driver of costeffectiveness.

Conclusion: The treatment algorithm recommended in UK clinical practice represents a costeffective approach for the management of COPD. The addition of roflumilast to the standard of care regimens is a clinical and cost-effective treatment option for patients with severe COPD, who continue to exacerbate despite existing bronchodilator therapy.

Keywords: COPD, treatment, exacerbations, economic, cost-effectiveness, modeling

\section{Introduction}

Chronic obstructive pulmonary disease (COPD) is a progressive respiratory illness characterized by nonreversible airflow limitation and exacerbations. COPD is predominantly caused by tobacco smoke and is a major cause of morbidity and mortality worldwide, with an adult (aged $\geq 40$ years) population prevalence in
Correspondence: Kevin Jameson

MSD Ltd, Hertford Road, Hoddesdon,

Hertfordshire ENII 9BU, UK

Tel +44 1992452120

Fax +441992705120

Email kevin.jameson@merck.com 
the region of $10 \%{ }^{1}$ Based on 2009/2010 data from the Quality and Outcomes Framework, there were 861,341 and 62,744 patients with diagnosed COPD in England and Wales, respectively (924,085 in total). ${ }^{2,3}$ Consequently, the treatment and management of COPD has implications not only for patients but also for health care providers due to the significant burden it places on health care budgets.

The most common symptom of COPD is a shortness of breath caused by the narrowing of the airways, but the major burden of the disease can be attributed to exacerbations, which are events characterized by an increase in the frequency and intensity of symptoms such as dyspnea, cough, and sputum production. Exacerbations are important events as they have a significant impact on patients' quality of life and also may lead to an increased risk of mortality. ${ }^{4}$

Exacerbations also have an economic impact due to an increase in health care resource use for disease management and treatment of exacerbations, especially when hospitalization is required. The reduction of COPD exacerbations, therefore, represents an important goal of COPD therapy, both for improvement of patients' quality of life and for efficient use of limited health care resources.

The Global Initiative for Chronic Obstructive Lung Disease (GOLD) system classifies four COPD stages, based on the level of post-bronchodilator forced expiratory volume achieved in one second, as a percentage predicted of that for the general population (forced expiratory volume in 1 second $\left[\mathrm{FEV}_{1}\right] \%$ predicted): mild $\left(\mathrm{FEV}_{1} \geq 80 \%\right)$; moderate $\left(\mathrm{FEV}_{1}\right.$ 50\%-79\%); severe $\left(\mathrm{FEV}_{1} 30 \%-49 \%\right)$; very severe $\left(\mathrm{FEV}_{1}<30 \%\right){ }^{5}$

In the UK, the recent clinical guidelines from the National Institute for Health and Clinical Excellence (NICE) ${ }^{6}$ recommend alternative treatment approaches, depending on the level of $\mathrm{FEV}_{1}$ as a percentage of that predicted for the general population. For patients with $\mathrm{FEV}_{1}<50 \%$ predicted who continue to exacerbate or experience persistent breathlessness, the guideline recommends treatment with either a long-acting muscarinic antagonist (LAMA), or combination treatment with a long-acting beta agonist and inhaled corticosteroid (LABA/ICS). If ICS is declined or not tolerated by patients, a combination of LABA + LAMA should be considered. When a patient continues to experience persistent exacerbations or remains breathless, $\mathrm{LAMA}+\mathrm{LABA} / \mathrm{ICS}$ is the recommended treatment regimen. The NICE guidelines were developed prior to the approval of roflumilast by the European Medicines Agency (EMEA) in July $2010,{ }^{7}$ and therefore, no recommendations on this agent were incorporated in the guidelines.
Despite the range of available therapies to manage COPD, there is still an unmet need for patients with severe and very severe COPD who continue to exacerbate. A recent study (ECLIPSE), ${ }^{8}$ which aimed to investigate novel endpoints in COPD disease progression and provide a greater insight into patient needs, included an evaluation of the proportion of patients with two or more exacerbations (requiring antibiotics, corticosteroids, or both, or requiring hospitalization) in the last 12 months. The study findings suggested that approximately a third of patients with severe COPD and almost half of patients with very severe COPD had two or more exacerbations per year. ${ }^{8}$ As more than half the study population consisted of patients with severe and very severe COPD, this study has confirmed a significant unmet need in the management of COPD for both patients and health care providers.

Roflumilast is an oral, once-daily selective phosphodiesterase-4 inhibitor with a broad range of anti-inflammatory actions, which has recently received a license for use as maintenance treatment for COPD as an add-on to bronchodilators. As proven in clinical trials, roflumilast reduced the rate of exacerbations in patients with severe airflow obstruction and a history of frequent exacerbations, whose COPD is associated with chronic bronchitis. ${ }^{9-12}$ The objective of this study was to estimate the lifetime cost and health outcomes associated with the different treatment options available for the management of severe COPD in the UK setting in a fully incremental cost-effectiveness analysis.

\section{Materials and methods Model structure and cohort}

A cohort state-transition Markov model was constructed to estimate the lifetime cost and health outcomes of adding roflumilast to therapeutic regimens in patients with severe and very severe COPD, associated with chronic bronchitis, who have a history of frequent exacerbations and continue to exacerbate, despite existing bronchodilator therapy.

Markov cohort models, which consider cohorts of patients and are frequently used in cost-effectiveness analyses, are particularly useful in the modeling of chronic disease, as long term costs and outcomes can be estimated by running the model for a large number of cycles (known as Markov cycles). Patients move between mutually exclusive health states in the model based on a set of transition probabilities, which are assigned over a discrete period of time (matching the Markov cycle length). For each health state a certain cost and health outcome is specified. ${ }^{13}$ 
The Markov model developed for this analysis was implemented in TreeAge Pro Suite 2009 (TreeAge Software Inc, Williamstown, MA) with a Microsoft ${ }^{\circledR}$ Office Excel 2003 (Microsoft Corporation, Redmond, WA) front-end and was based on a published COPD model..$^{14}$ The relative rate ratios (RRRs) of exacerbation for alternative treatment regimens were calculated based on the results of a recently published mixed treatment comparison (MTC). ${ }^{15}$ Using the complete set of RRRs, this analysis was the first to simultaneously compare various treatment regimens commonly used for the management of COPD, via a fully incremental analysis. Furthermore, where earlier published models compared alternative treatment regimens used at a defined stage in the treatment pathway, the current model allowed patients to progress from a first-line to a second-line treatment regimen, simulating escalation in the COPD treatment regimen when a patient continues to exacerbate. The transition from a first-line to second-line treatment regimen was determined by the average time on the first-line regimen, assumed to be 1 year in the base case.

The model included five Markov states: severe COPD, first-line regimen $\left(\mathrm{S}_{1}\right)$; severe $\mathrm{COPD}$, second-line regimen $\left(\mathrm{S}_{2}\right)$; very severe COPD, first-line regimen $\left(\mathrm{VS}_{1}\right)$; very severe COPD, second-line regimen $\left(\mathrm{VS}_{2}\right)$; and death (Figure 1). A detailed model diagram representing transitions is presented in the Appendix (Figure A1).

The $\mathrm{S}_{1}$ health state represents patients with severe COPD, who continued to exacerbate, despite their current treatment regimen. The $S_{2}$ health state corresponds to patients with severe COPD who initially received first-line treatment, but continued to exacerbate, or remained breathless on the firstline therapy. It was assumed that these patients were switched to a second-line regimen. The $\mathrm{VS}_{1}$ health state describes patients who were on a first-line treatment regimen and progressed from severe to very severe $\mathrm{COPD}$, while remaining on first-line treatment. The $\mathrm{VS}_{2}$ health state represents: (a) patients who were on a first-line treatment regimen in the very severe COPD state $\left(\mathrm{VS}_{1}\right)$, and who were then switched to a secondline regimen; (b) patients who were on a second-line treatment in the severe COPD state $\left(\mathrm{S}_{2}\right)$, and then progressed to very severe COPD, continuing the second-line treatment, and; (c) patients initially in the $S_{1}$ health state, who were switched to a second-line treatment regimen upon disease progression to very severe COPD (this transition was not modeled in the base case, but explored in scenario analysis F). As mentioned above, a change from first- to second-line treatment depended on the average time on the first-line regimen and was not explicitly linked to the events of exacerbation. The severe $\left(\mathrm{S}_{1}\right.$ and $\mathrm{S}_{2}$ ) and very severe $\left(\mathrm{VS}_{1}\right.$ and $\left.\mathrm{VS}_{2}\right)$ COPD health states are based on the definition of severity by GOLD criteria, 5 ie, using postbronchodilator $\mathrm{FEV}_{1} \%$ predicted, relative to a general (non-COPD) population. ${ }^{16}$

The Markov state 'Death' included mortality, modeled using a combination of background mortality from UK life tables adjusted to the standardized mortality ratio (SMR) for COPD, and mortality due to hospital-treated exacerbations. The hospital case fatality rate (CFR), ie, the percentage of patients who died during a hospital-treated exacerbation amounted to $7.7 \%$, as reported in the UK National Chronic Obstructive Pulmonary Disease Audit 2008. ${ }^{17}$ The audit reports data on 9,716 COPD admissions for exacerbations, and found that the mortality rate in the 90 days following admission was $13.9 \%$, with COPD or complication of COPD being the cause of death in $65 \%$ of mortality cases. The hospital CFR used in the model assumed that all COPD deaths occur during the hospital stay, and within the same cycle as the exacerbation. The cycle length in the model was 1 month and the time horizon was 30 years.

The mean age of patients in the cohort was 64 years at the start of the model. The baseline characteristics of the modeled

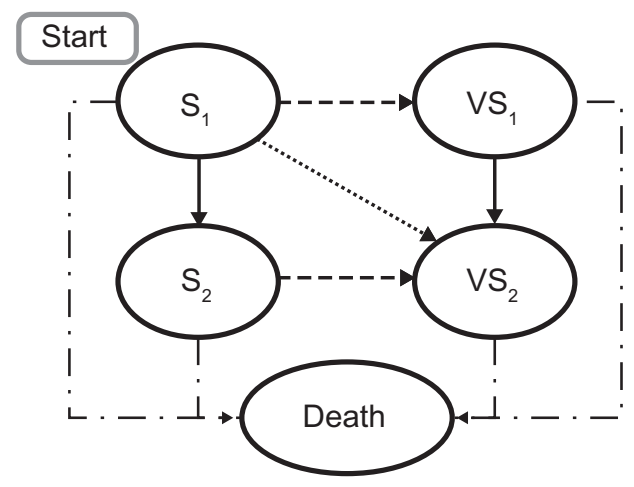

Figure I Simplified Markov cohort model structure. Note: Arrows represent the possible pathways of the disease course.

\footnotetext{
$\longrightarrow$ Patients who continue to exacerbate or remain breathless are switched to a second line regimen

$--\rightarrow$ Patients who progress to very severe COPD

$-\rightarrow$ Patients who die due to background mortality and hospital mortality

....... Patients who are switched to a second line regimen upon disease pregression (explored in a scenario analysis only)
} 
cohort were based on the pooled analysis of the M2-124 and M2-125 clinical trials of roflumilast. ${ }^{9}$

Within each model cycle the patients in the cohort were at risk of an exacerbation, which could be community-treated or hospital-treated.

Costs were calculated from the perspective of the UK National Health Service (NHS). The model estimated total costs, life-years (LYs), quality-adjusted life-years (QALYs) and exacerbations per patient. A discount rate was applied to both costs and outcomes to adjust for differential timing, and hence allow a comparison of costs and outcomes in terms of a net present value. ${ }^{13}$ In accordance with the NICE reference case, costs and outcomes (LYs, QALYs) were discounted at a rate of $3.5 \%$ per annum. ${ }^{18}$

A variety of scenario analyses were conducted to investigate the effect of uncertainties in the base case assumptions on the model results.

\section{Clinical management of COPD patients (pathway in the model)}

Costs and health outcomes related to the treatment of COPD were simulated for two patient groups: ICS-tolerant patients and ICS-intolerant patients (including patients who decline ICS). A range of first-line treatments were analyzed for both groups (Table 1). As roflumilast is indicated for the maintenance treatment of severe COPD $\left(\mathrm{FEV}_{1}\right.$ post-bronchodilator $\leq 50 \%$ predicted) associated with chronic bronchitis in patients with a history of frequent exacerbations as an add-on to bronchodilator treatment, ${ }^{7}$ patients in the model were assumed to continue to

Table I COPD therapeutic regimens

\begin{tabular}{ll}
\hline ICS-tolerant patients & ICS-intolerant patients \\
\hline First line treatment options & \\
LABA & LABA \\
LAMA & LAMA \\
LABA + roflumilast & LABA + roflumilast \\
LAMA + roflumilast & LAMA + roflumilast \\
LAMA + LABA & LAMA + LABA \\
LAMA + LABA + roflumilast & LAMA + LABA + roflumilast \\
LABA/ICS & \\
LABA/ICS + roflumilast & \\
LAMA + LABA/ICS & \\
LAMA + LABA/ICS + roflumilast & \\
Second line treatment options & \\
LAMA + LABA/ICS & LAMA + LABA \\
\hline
\end{tabular}

Note: alf patients continue to exacerbate, despite existing treatment.

Abbreviations: COPD, chronic obstructive pulmonary disease; ICS, inhaled corticosteroids; LABA, long-acting beta agonist; LAMA, long-acting muscarinic antagonist. exacerbate despite current therapy. It was assumed that ICStolerant patients and ICS-intolerant patients would receive LAMA + LABA/ICS and LAMA + LABA, respectively, if they continued to exacerbate. Such an approach is consistent with the current recommendations of NICE CG101, ${ }^{6}$ and was assumed to be common across all first-line treatment options included in the model.

\section{COPD progression and transition probabilities}

The calculation of the average time a patient spends in a particular health state was similar to the methods used and published elsewhere. ${ }^{19}$ The assessed patient population was assumed to have severe COPD at baseline, with lung function in the middle of the severe COPD FEV ${ }_{1} \%$ range $(40 \%$ predicted), and continued to exacerbate despite their current treatment regimen.

Continuous transition probabilities for progression from severe to very severe COPD were calculated as the reciprocal of the estimated average time $(\mathrm{T})$ in the severe COPD states $\left(\mathrm{S}_{1}\right.$ and $\left.\mathrm{S}_{2}\right)$, and based on the rate of decline in lung volume in patients with COPD $(0.052 \mathrm{~L} \text { per year })^{20}$ relative to the natural rate of decline of lung volume in the general (non-COPD) population. ${ }^{16}$ The dotted line in Figure 2 represents the level of lung function at which $\mathrm{FEV}_{1}$ is $30 \%$ of the level predicted for the general adult population, at any given age. The solid line represents the declining lung volume in the modeled cohort of patients who start in severe COPD. The predicted intersection of these lines determines the average time $(\mathrm{T})$ in the severe COPD states $\left(\mathrm{S}_{1}\right.$ and $\left.\mathrm{S}_{2}\right)$, before progressing to one of the very severe COPD states $\left(\mathrm{VS}_{1}\right.$ and $\left.\mathrm{VS}_{2}\right)$.

\section{Exacerbations}

For the purpose of running the fully incremental analysis, the rates of exacerbations for each treatment regimen were expressed in relative terms to a common reference regimen. LAMA + LABA/ICS was used as the reference regimen, with an assumed exacerbation rate of 2.0 per patient per year in the severe COPD states (community - or hospital-treated). The baseline exacerbation rate for the very severe states was 2.4 exacerbations per year, calculated by applying the ratio of rates of exacerbations in patients with severe and very severe COPD from the pooled analysis of the M2-124 and M2-125 clinical trials of roflumilast to the baseline rate of exacerbations in the severe state. The efficacy of each treatment regimen versus the reference regimen was expressed as an RRR of exacerbations. Due to a lack of direct 


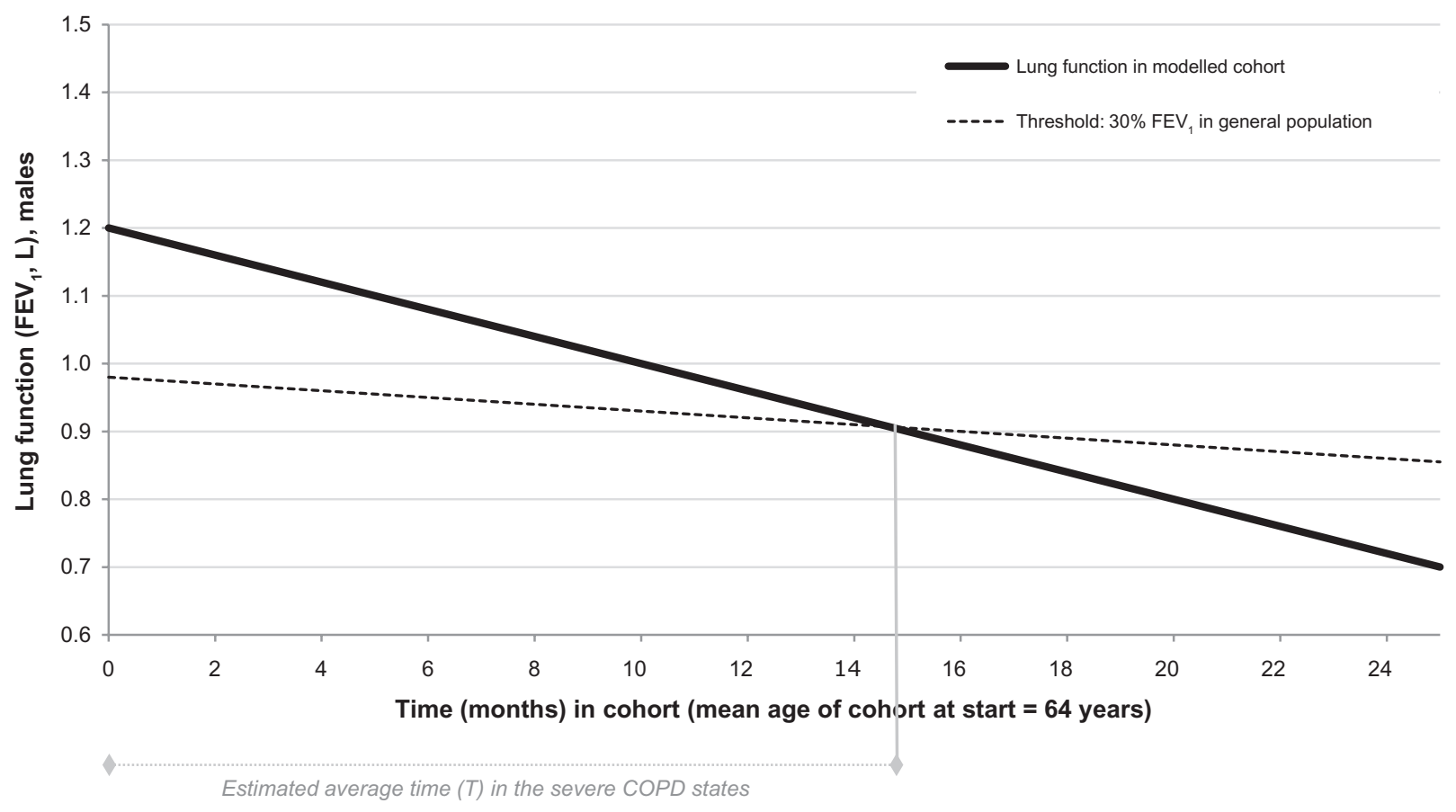

Figure 2 Time to disease progression in patients starting in the severe COPD state (illustrative example).

Abbreviations: COPD, chronic obstructive pulmonary disease; $\mathrm{FEV}_{1}$, forced expiratory volume in one second.

clinical trial evidence for several treatment combinations of interest, the RRRs of exacerbations were calculated from the results of the additive main effects model of the published MTC, ${ }^{15}$ as shown in Table 2. The RRR of exacerbations was assumed to be the same in both severe and very severe COPD states. It was also assumed that the RRRs can be applied to exacerbations without distinguishing between community-treated or hospital-treated exacerbations, as the data to differentiate between the two types of exacerbations were not available. Treatment-related improvements in lung function were not considered in the model.

\section{Health-related utilities}

Patients' preferences for a preferred outcome (or health state) are represented in the form of utility values, bounded between 0 (death) and 1 (perfect health). To calculate QALYs, one LY was multiplied by the utility value associated with a particular health state. Two different types of utility were applied in

Table 2 RRR of exacerbations for treatments versus the common reference regimen (LAMA + LABA/ICS), based on the results of the additive mixed treatment comparison 15

\begin{tabular}{|c|c|c|c|c|}
\hline Treatment & $\begin{array}{l}\text { Reference } \\
\text { regimen }\end{array}$ & $\begin{array}{l}\text { RRR of } \\
\text { exacerbations }\end{array}$ & $95 \% \mathrm{Cl}$ & $\begin{array}{l}\text { Predicted no of } \\
\text { exacerbations } \\
\text { per year }^{\mathrm{a}}\end{array}$ \\
\hline LABA & & 1.65 & $1.46-1.88$ & 3.29 \\
\hline LAMA & & 1.41 & $1.28-1.57$ & 2.83 \\
\hline LABA + roflumilast & & 1.38 & $1.16-1.66$ & 2.75 \\
\hline LAMA + roflumilast & & 1.18 & $1.01-1.39$ & 2.36 \\
\hline LAMA + LABA & Versus & 1.22 & $1.14-1.32$ & 2.44 \\
\hline LABA/ICS & $L A M A+L A B A / I C S$ & 1.35 & $1.23-1.49$ & 2.70 \\
\hline LAMA + LABA + roflumilast & & 1.02 & $0.88-1.18$ & 2.04 \\
\hline LABA/ICS + roflumilast & & 1.13 & $0.97-1.33$ & 2.25 \\
\hline LAMA + LABA/ICS & & 1.00 & $0.70-1.30$ & 2.00 \\
\hline LAMA + LABA/ICS + roflumilast & & 0.84 & $0.74-0.95$ & 1.68 \\
\hline
\end{tabular}

Notes: Predicted number of exacerbations per year in first line, severe COPD. Calculated relative to the common reference regimen, which is associated with an assumed background exacerbation rate of 2.0 exacerbations per year.

Abbreviations: RRR, relative rate ratio; $\mathrm{Cl}$, confidence interval; LABA, long-acting beta agonist; LAMA, long-acting muscarinic antagonist; ICS, inhaled corticosteroids. 
the model: Firstly, utility associated with the severe $(0.751)$ and very severe (0.657) COPD health states, which were based on EQ-5D data obtained from the pooled analysis of the M2-124 and M2-125 clinical trials of roflumilast. ${ }^{9}$ The second type were the annual decrements in utility due to a community-treated exacerbation $(-0.01)$ and a hospitaltreated exacerbation $(-0.042)$, which were taken from a published study. ${ }^{21}$ The absolute reduction of utility due to a community-treated exacerbation that applies for one year was accounted for within the 1-month model cycle by recalculating as $0.01 \times 12=0.12$, and deducted from the baseline utilities in severe and very severe COPD states. Equally, the absolute reduction of utility due to a hospital-treated exacerbation that applied for one year was accounted for by recalculating as $0.042 \times 12=0.504$ and deducted from the baseline utilities.

Adverse events (AEs) related to treatment were assumed to be mild and transient in nature, and not to impact healthrelated quality of life or costs.

Those patients who did not tolerate ICS were presumed to enter the model after an earlier trial of the agent. Subsequent discontinuation and related AEs were, therefore, not taken into account.

\section{Costs and cost perspective}

The perspective of the economic analysis was that of the UK NHS payer. Only direct medical costs related to COPD treatment were included. Costs were represented across three groups: (a) costs of maintenance of patients in the severe and very severe COPD states (excluding COPD drugs); (b) costs of COPD drugs; and (c) costs of community- and hospitaltreated exacerbations. Drug costs were sourced from the 2011 British National Formulary (BNF 61). ${ }^{22}$ Monthly maintenance costs for severe and very severe COPD were derived from the NHS National Schedule of Reference Costs 2009/1023 and the published literature. ${ }^{24}$ Costs of a community-treated exacerbation were compiled based on the resource use stated in the report by the GOLD Strategy Group, ${ }^{5}$ and combined with cost data from the NHS Reference Costs, ${ }^{23}$ the Personal Social Services Research Unit $2010^{25}$ and the BNF 61. ${ }^{22}$ In order to calculate the costs of a hospital-treated exacerbation, costs for relevant COPD-related health care resource groups (HRGs) were weighted by the reported annual number of episodes, with data being taken from the NHS Reference Costs. ${ }^{23}$ Further, it was assumed that $90 \%$ of patients would arrive at the hospital by ambulance. Therefore $90 \%$ of the HRG cost for ambulance transportation was added to the weighted COPD HRG costs. A summary of the costs per model cycle and per exacerbation are presented in Table 3 whereas tables with detailed calculation are provided in the appendix (Tables A1 and A2).

\section{Results}

Two fully incremental analyses were performed separately for ICS-tolerant and ICS-intolerant COPD patients. In the analysis the total costs, LYs, QALYs, and the number of exacerbations per patient were calculated for each treatment over a time horizon of 30 years (lifetime analysis). Table 4 shows the results for both populations.

Table 3 Costs per model cycle (summary)

\begin{tabular}{|c|c|}
\hline Cost component & $\begin{array}{l}\text { Costs per cycle } \\
\text { in GBP }\end{array}$ \\
\hline Roflumilast (Daxas ${ }^{\circledR}$, Nycomed, Zurich, Switzerland) & 38.23 \\
\hline $\begin{array}{l}\text { LABA } \\
\text { Salmeterol (Serevent }{ }^{\circledR} \text { Evohaler }^{\circledast}, \text { Accuhaler }^{\circledast} \text {, and Diskhaler }{ }^{\circledast}, \text { GlaxoSmithKline, Brentford, UK) }\end{array}$ & 29.67 \\
\hline $\begin{array}{l}\text { LAMA } \\
\text { Tiotropium (Spiriva }{ }^{\circledR} \text {, Boehringer Ingelheim, Ingelheim, Germany) }\end{array}$ & 32.33 \\
\hline $\begin{array}{l}\text { LABA/ICS } \\
\text { Salmeterol/fluticasone (Seretide }{ }^{\circledast} 500 \text { Accuhaler, GlaxoSmithKline) }\end{array}$ & 41.49 \\
\hline $\begin{array}{l}\text { Maintenance, severe COPD } \\
\text { Includes outpatient visit respiratory physician, spirometry, influenza vaccination and oxygen therapy }\end{array}$ & 48.33 \\
\hline $\begin{array}{l}\text { Maintenance, very severe COPD } \\
\text { Includes outpatient visit respiratory physician, spirometry, influenza vaccination and oxygen therapy }\end{array}$ & 150.05 \\
\hline $\begin{array}{l}\text { Community-treated exacerbation } \\
\text { Includes general practitioner (consultation lasting II.7 minutes), Accident \& Emergency } \\
\text { services (not admitted), prednisolone and co-amoxiclav }\end{array}$ & 73.56 \\
\hline $\begin{array}{l}\text { Hospital-treated exacerbation } \\
\text { Includes HRG codes DZ2IA-H, DZ2IJ-K and ambulance transportation }\end{array}$ & $\mathrm{I}, 346.63$ \\
\hline
\end{tabular}


Based on the results of the fully incremental analyses, total costs and total QALYs obtained for each treatment were plotted on a single graph (a cost-effectiveness plane), and were used to generate a cost-effectiveness frontier. The frontier indicates those treatment regimens which represent the most cost-effective use of NHS resources, ie, where QALY-yield is maximized for a given level of cost, or where cost is minimized for a given level of QALY-yield. Any point above, or to the left of the frontier represents an inefficient use of resources as higher benefit can be achieved at equal or lower costs. Such points are referred to as being "dominated", either by direct dominance (being more costly and less effective than a comparator), or by extended dominance (where the ICER for a particular treatment is higher than the next most effective treatment). ${ }^{26}$

For ICS-tolerant patients (Figure 3A) the cost-effectiveness frontier analysis suggested starting patients on a first-line treatment with LABA or LAMA. For patients who continue to exacerbate, LAMA + LABA/ICS presents a costeffective option for a second-line treatment (versus LAMA), followed by LAMA + LABA/ICS + roflumilast (versus $\mathrm{LAMA}+\mathrm{LABA} / \mathrm{ICS}$ ). The remaining treatment options are either excluded due to direct or extended dominance.

The cost-effectiveness frontier analysis for ICS-intolerant patients (Figure 3B) suggests starting patients on LABA or LAMA. If patients continue to exacerbate, LAMA + LABA is a cost-effective second-line option, followed by LAMA + LABA + roflumilast (versus LAMA + LABA).

As with the results of the analysis of patients who are able to use ICS, these results are in line with the escalation of treatment recommended in NICE CG101. ${ }^{6}$ Further, for both patient groups, the results suggest the use of roflumilast in addition to the standard of care (LAMA + LABA/ICS or LAMA + LABA, respectively).

Based on the cost-effectiveness frontiers, two comparisons of particular interest were selected: LABA/ ICS + LAMA + roflumilast versus LABA/ICS + LAMA for ICS-tolerant patients and LABA + LAMA + roflumilast versus LABA + LAMA for ICS-intolerant patients. These comparisons of interest were subject to further investigation as they are likely to indicate the most common uses of roflumilast in clinical practice, within each patient group. Extensive sensitivity analyses were also conducted for these comparisons.

As presented in Table 5, LAMA + LABA/ICS + roflumilast versus LAMA + LABA/ICS yielded an ICER of £16,566/ QALY gained in ICS-tolerant patients and would therefore normally be considered as cost-effective when applying commonly accepted thresholds for cost-effectiveness by NICE (£20,000 to $£ 30,000$ per QALY gained). ${ }^{18}$ The comparison of LAMA + LABA + roflumilast versus LAMA + LABA for ICS-intolerant patients yielded an ICER of $£ 13,764$ / QALY gained.

\section{Sensitivity and scenario analyses}

To examine the impact of parameter uncertainties on the results of the analyses, probabilistic sensitivity analysis (PSA) was performed for both key comparisons of interest. Appropriate distributions were assigned to key model parameters and 1000 simulations were run. Results of the simulations for ICS-tolerant patients are presented as an incremental costeffectiveness scatter-plot (Figure 4A) and cost-effectiveness acceptability curve (CEAC), which suggests that the probability of LAMA + LABA/ICS + roflumilast being

Table 4 Results of fully incremental cost-effectiveness analysis (base case)

\begin{tabular}{|c|c|c|c|c|c|c|c|c|}
\hline \multirow[t]{2}{*}{ Treatment } & \multicolumn{2}{|c|}{ Costs in GBP } & \multicolumn{2}{|c|}{ Exacerbations $^{a}$} & \multicolumn{2}{|l|}{ LYs } & \multicolumn{2}{|l|}{ QALYs } \\
\hline & $\begin{array}{l}\text { ICS- } \\
\text { tolerant }\end{array}$ & $\begin{array}{l}\text { ICS- } \\
\text { intolerant }\end{array}$ & $\begin{array}{l}\text { ICS- } \\
\text { tolerant }\end{array}$ & $\begin{array}{l}\text { ICS- } \\
\text { intolerant }\end{array}$ & $\begin{array}{l}\text { ICS- } \\
\text { tolerant }\end{array}$ & $\begin{array}{l}\text { ICS- } \\
\text { intolerant }\end{array}$ & $\begin{array}{l}\text { ICS- } \\
\text { tolerant }\end{array}$ & $\begin{array}{l}\text { ICS- } \\
\text { intolerant }\end{array}$ \\
\hline LABA & 22,342 & 21,477 & 23.48 & 26.67 & 8.06 & 7.75 & 5.39 & 5.13 \\
\hline LAMA & 22,370 & 21,500 & 23.16 & 26.37 & 8.10 & 7.79 & 5.42 & 5.17 \\
\hline LABA + roflumilast & 22,749 & 21,879 & 23.11 & 26.32 & 8.11 & 7.79 & 5.43 & 5.17 \\
\hline LAMA + roflumilast & 22,779 & 21,905 & 22.84 & 26.06 & 8.14 & 7.83 & 5.46 & 5.20 \\
\hline LAMA + LABA & 22,687 & 21,814 & 22.89 & 26.11 & 8.14 & 7.82 & 5.45 & 5.19 \\
\hline $\mathrm{LAMA}+\mathrm{LABA}+$ roflumilast & 23,100 & 22,222 & 22.61 & 25.85 & 8.18 & 7.86 & 5.48 & 5.22 \\
\hline LABA/ICS & 22,468 & - & 23.07 & - & 8.11 & - & 5.43 & - \\
\hline LABA/ICS + roflumilast & 22,878 & - & 22.76 & - & 8.16 & - & 5.46 & - \\
\hline $\mathrm{LAMA}+\mathrm{LABA} / \mathrm{ICS}$ & 22,816 & - & 22.58 & - & 8.18 & - & 5.48 & - \\
\hline $\begin{array}{l}\mathrm{LAMA}+\mathrm{LABA} / \mathrm{ICS}+ \\
\text { roflumilast }\end{array}$ & 23,230 & - & 22.35 & - & 8.21 & - & 5.51 & - \\
\hline
\end{tabular}

Note: ${ }^{a}$ Exacerbation rates were not discounted.

Abbreviations: GBP, British pound; LY, life year; QALY, quality-adjusted life year; ICS, inhaled corticosteroids; LABA, long-acting beta agonist; LAMA, long-acting muscarinic antagonist. 

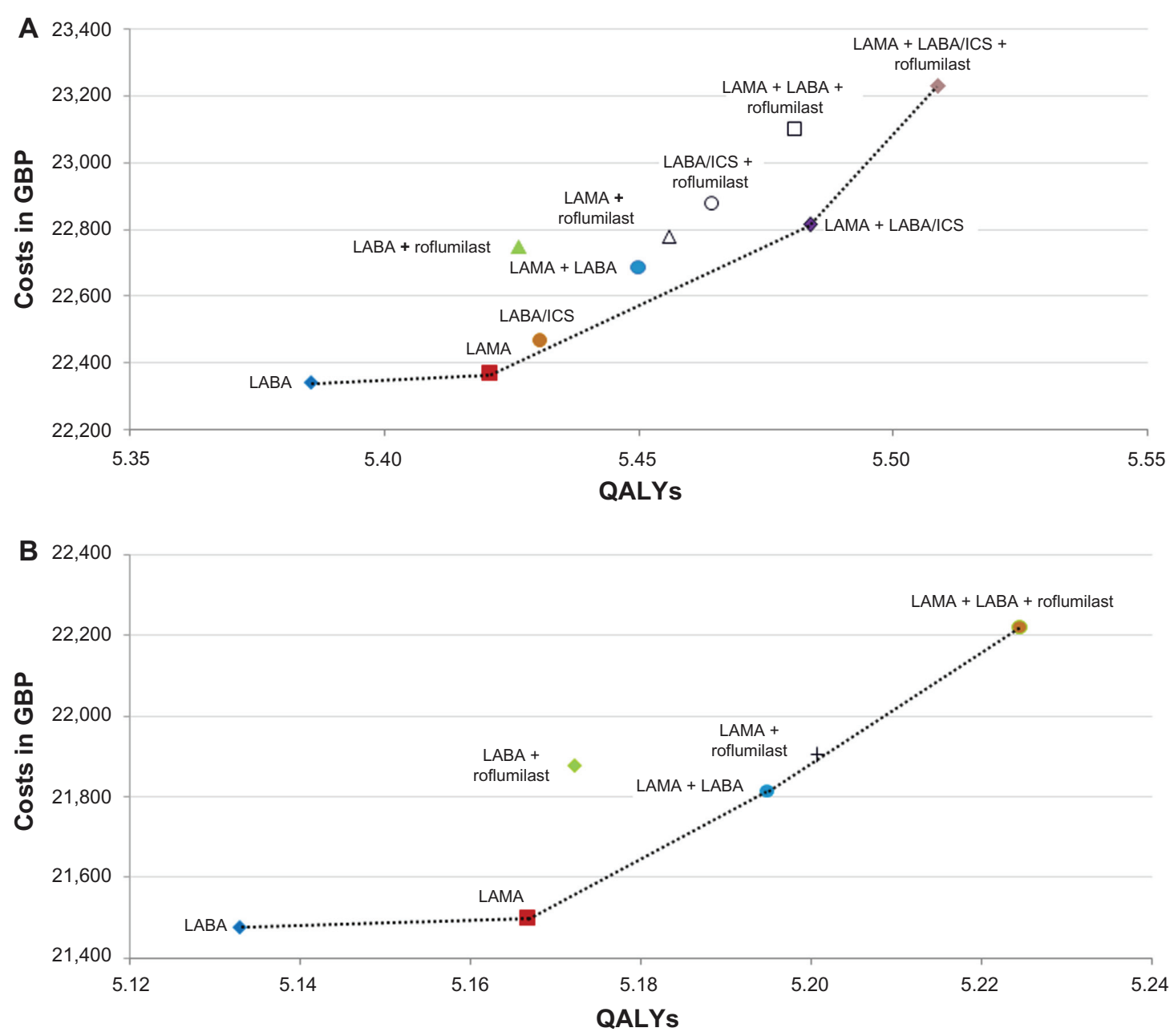

Figure 3 Cost-effectiveness-frontier analysis for ICS-tolerant patients (A) and ICS-intolerant patients (B).

Abbreviations: GBP, British pound; QALY, quality-adjusted life year; LABA, long-acting beta agonist; LAMA, long-acting muscarinic antagonist; ICS, inhaled corticosteroids.

cost-effective versus LAMA + LABA/ICS exceeds $80 \%$, at a willingness-to-pay $£ 30,000$ per QALY gained (Figure 4B). The PSA for ICS-intolerant patients provided similar results (analysis not presented).

In order to test the sensitivity of the base case ICER to uncertainties in individual model parameters, one-way sensitivity analysis (OWSA) was performed. In the OWSA, plausible ranges of different model parameters were first identified, using the boundaries of the $95 \%$ confidence intervals where possible. In separate model runs, each parameter in turn was set first at its upper estimate and then at its lower estimate while the remaining variables were set at their base case values.

The tornado diagram depicts the variation of the ICER ( $£ /$ QALY gained) of LAMA + LABA/ICS + roflumilast versus LAMA + LABA/ICS, from the base case value of $£ 16,566 /$ QALY gained, at lower and upper estimate of the value of each parameter. The key drivers of cost-effectiveness for ICS-tolerant patients were the relative rate of exacerbations between the assessed treatment regimens versus the common reference regimen (Figure 5). The OWSA for ICS-intolerant patients provided similar results, with the ICER showing greatest sensitivity to change in the relative rate of exacerbation between the assessed treatment regimen versus the common reference regimen (analysis not presented).

The effect of changes in the assumptions incorporated in the base case on model results were evaluated in various scenario analyses, focusing on the comparisons of interest.

Scenario analysis A: The background exacerbation rate (ie, the number of exacerbations per year in the severe COPD state for the common reference regimen [LAMA + LABA/ ICS]) was adjusted from a base case value of 2 exacerbations to 1 and 3 exacerbations.

Scenario analysis B: Incorporation of a change in lung function of $+46 \mathrm{~mL}$ with the roflumilast regimens, relative 
Table 5 Results for comparisons of interest (base case)

\begin{tabular}{|c|c|c|c|c|c|}
\hline & \multicolumn{3}{|c|}{ Outcomes } & \multicolumn{2}{|l|}{ ICER } \\
\hline & $\begin{array}{l}\text { Costs } \\
\text { in GBP }\end{array}$ & LYs & QALYs & $\begin{array}{l}\text { GBP per } \\
\text { LY gained }\end{array}$ & $\begin{array}{l}\text { GBP per } \\
\text { QALY gained }\end{array}$ \\
\hline \multicolumn{6}{|l|}{ ICS-tolerant patients } \\
\hline LAMA + LABA/ICS + roflumilast & 23,230 & 8.21 & 5.51 & & \\
\hline LAMA + LABA/ICS & 22,816 & 8.18 & 5.48 & & \\
\hline Increment $^{\mathrm{a}}$ & 414 & 0.03 & 0.03 & 13,422 & 16,566 \\
\hline \multicolumn{6}{|l|}{ ICS-intolerant patients } \\
\hline LAMA + LABA + roflumilast & 22,222 & 7.86 & 5.22 & & \\
\hline LAMA + LABA & 21,814 & 7.82 & 5.19 & & \\
\hline Increment ${ }^{\mathrm{b}}$ & 408 & 0.04 & 0.03 & 11,156 & 13,764 \\
\hline
\end{tabular}

Notes: ${ }^{a} L A M A$ + LABA/ICS + roflumilast minus LAMA + LABA/ICS; 'LAMA + LABA + roflumilast minus LAMA + LABA.

Abbreviations: GBP, British pound; LY, life year; QALY, quality-adjusted life year; ICER, incremental cost-effectiveness ratio; ICS, inhaled corticosteroids; LABA, long-acting beta agonist; LAMA, long-acting muscarinic antagonist.

to the common reference regimen, based on results from the subgroup of patients who received LABA + roflumilast in the M2-124 and M2-125 clinical trials ${ }^{10}$ (base case: no lung function benefit). The duration of the lung function benefit was assumed to be 1 year. A lung function improvement would be expected to increase the time spent in a particular state, with resultant cost savings and quality of life benefit.

Scenario analysis C: Time on first-line therapy was adjusted to 0.5 years and 2 years (base case: 1 year).

Scenario analysis D: Patients remained on first-line therapy for the duration of the model, including those on
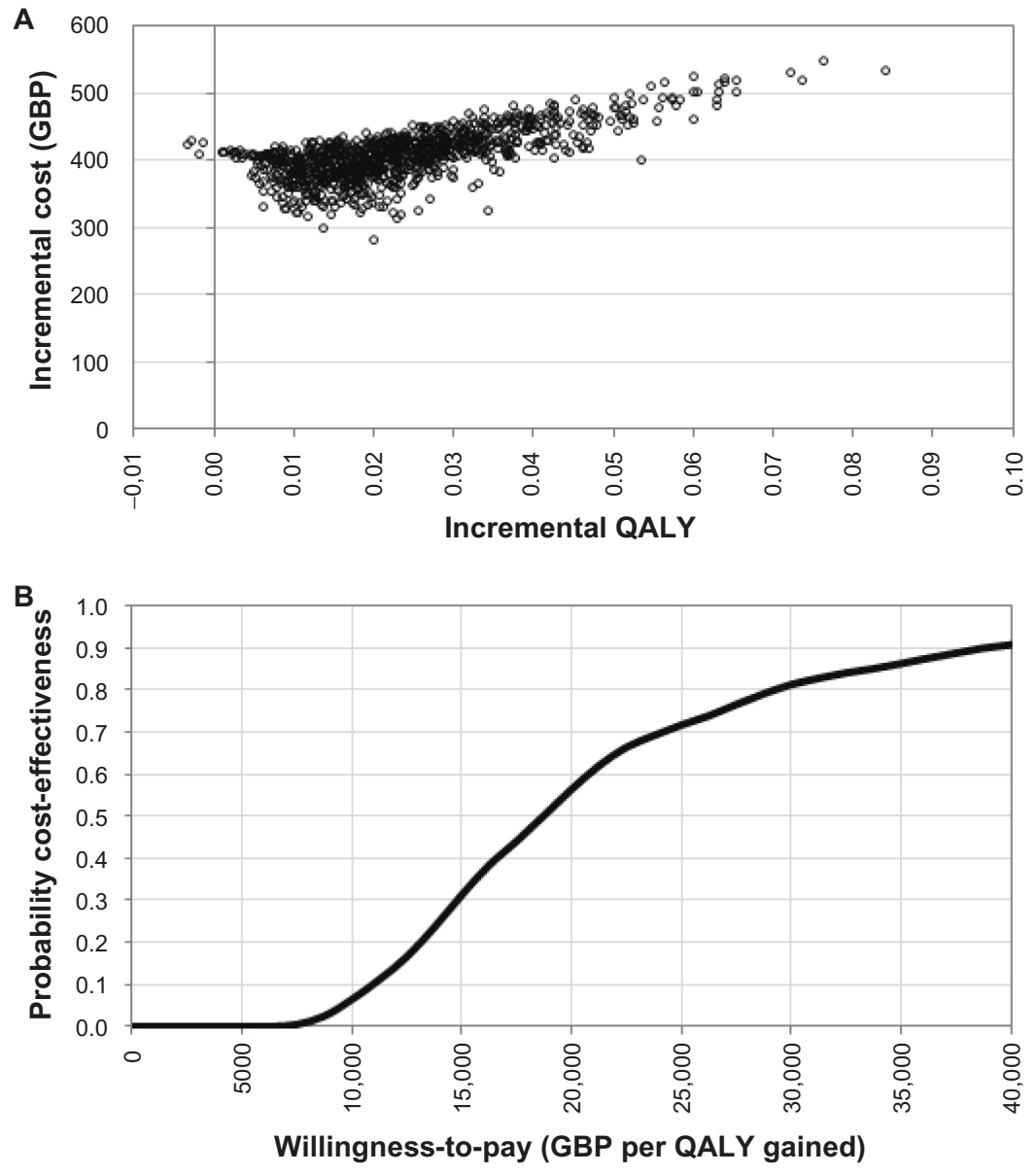

Figure 4 Incremental cost-effectiveness scatter plot (A) and CEAC (B), LAMA + LABA/ICS + roflumilast versus LAMA + LABA/ICS, I000 runs. 


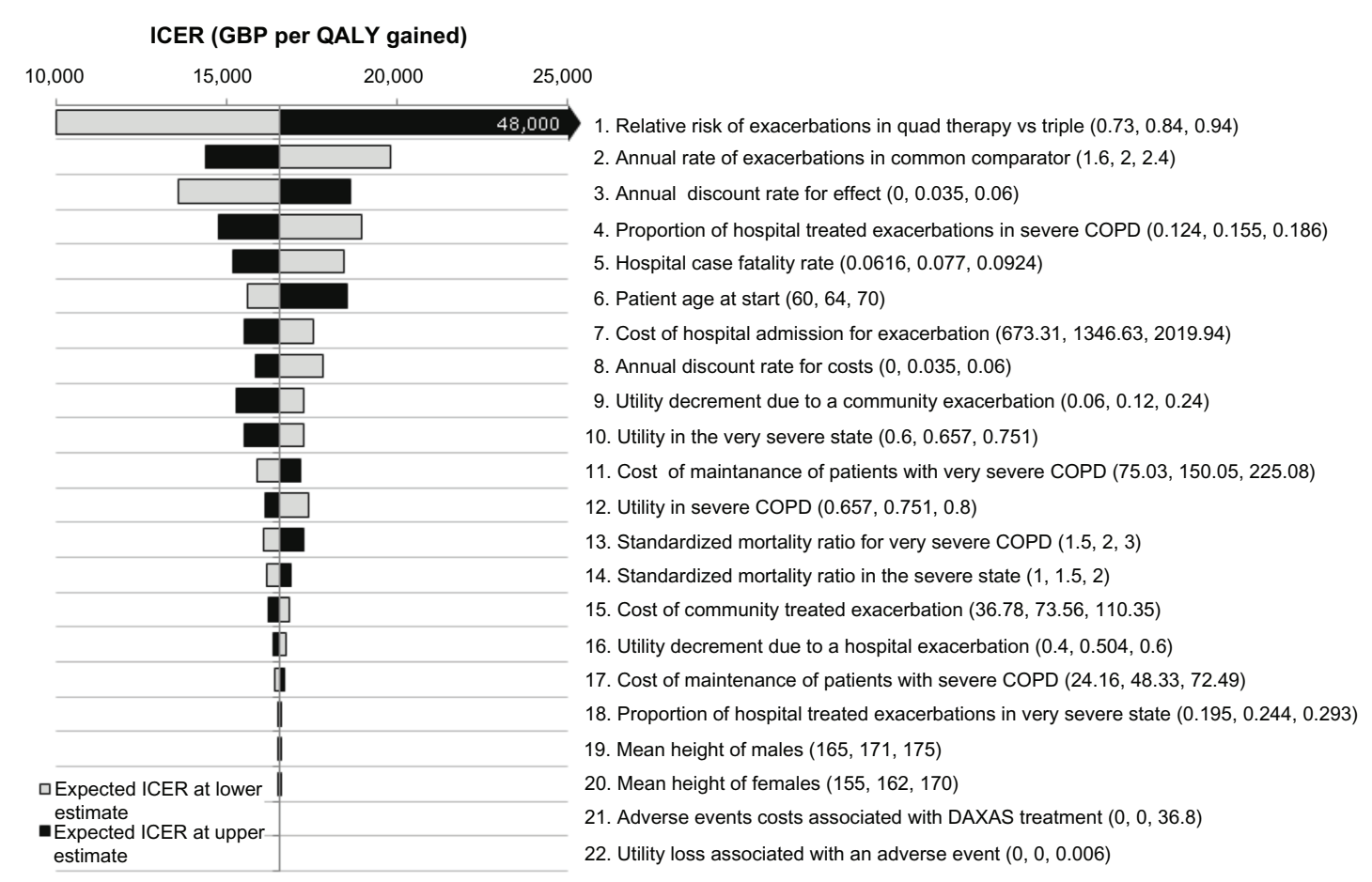

Figure 5 Tornado diagram, LAMA + LABA/ICS + roflumilast versus LAMA + LABA/ICS.

Note: The diagram depicts the variation of the ICER (GBP per QALY gained), from the base case value of $£$ I6,566/QALY gained, at lower and upper estimate of the value of each parameter. The middle of the tornado diagram corresponds to the base case ICER; the grey bars represent the cost-effectiveness at low estimate of each parameter and the black bars at high estimate.

Abbreviations: LABA, long-acting beta agonist; LAMA, long-acting muscarinic antagonist; ICS, inhaled corticosteroids; ICER, incremental cost-effectiveness ratio; GBP, British pound; QALY, quality-adjusted life year.

the comparator regimens (base case: patients were assumed to receive a second-line treatment which was common to all patients).

Scenario analysis E: Patients started treatment in very severe COPD health state (base case: severe COPD).

Scenario analysis F: Treatment regimen was switched following progression from severe to very severe COPD (base case: Switch from a first-line treatment regimen to a second-line regimen occurred 1 year after initiation of the first-line treatment regimen).

A summary of results for the scenario analyses within ICS-tolerant and ICS-intolerant patients for the comparison of interest is presented in Tables 6 and 7, respectively.

Results of the scenario analyses in both populations showed that the base case results were sensitive to changes in assumptions regarding the baseline rate of exacerbations for the common reference regimen in the severe COPD states (scenario A) and also the inclusion of lung function benefit (scenario B). As exacerbations are the primary efficacy input used in the model, and changes in lung function have an impact on disease progression (and hence cost and quality of life), it would be expected that these parameters would impact model results.
The base case assumption of patients moving to a secondline treatment after 1 year may vary in clinical practice, but scenario $\mathrm{C}$ showed that results are not sensitive to adjustment in this assumption. This is because simultaneously switching patients to a common second-line treatment regimen removes potential differences in benefits and costs between the initial treatment regimens being compared. Analyses also demonstrated the assumed second-line treatment regimen (scenario D), patients starting in the very severe COPD state (scenario E), and the assumption of switch to second-line therapy upon disease progression (scenario F).

\section{Discussion}

COPD continues to be a significant burden to health care systems around the world, despite the availability of multiple treatment options. In particular there remains an unmet need for ICS-tolerant and ICS-intolerant patients with severe COPD who are inadequately controlled on triple therapy (LAMA + LABA/ICS) and dual therapy (LAMA + LABA), respectively. As such it is important to understand the cost-effectiveness of different treatment options in order to optimize health outcomes to most efficiently use health care resources. 
Table 6 Results for scenario analyses, ICS-tolerant patients

\begin{tabular}{|c|c|c|c|c|c|}
\hline \multirow[t]{2}{*}{ Scenario } & \multicolumn{2}{|c|}{ Costs in GBPa } & \multicolumn{2}{|l|}{ QALYs $^{\mathbf{a}}$} & \multirow{2}{*}{$\begin{array}{l}\text { ICER (GBP per } \\
\text { QALY gained) } \\
\text { LAMA + LABA/ICS + } \\
\text { roflumilast versus } \\
\text { LAMA + LABA/ICS }\end{array}$} \\
\hline & $\begin{array}{l}\text { LAMA + } \\
\text { LABA/ICS }\end{array}$ & $\begin{array}{l}\text { LAMA + } \\
\text { LABA/CS + } \\
\text { roflumilast }\end{array}$ & $\begin{array}{l}\text { LAMA + } \\
\text { LABA/ICS }\end{array}$ & $\begin{array}{l}\text { LAMA + } \\
\text { LABA/ICS + } \\
\text { roflumilast }\end{array}$ & \\
\hline Base case & 22,816 & 23,230 & 5.4839 & 5.5089 & 16,566 \\
\hline A) Baseline number of exacerbations $=1$ & 22,464 & 22,881 & 6.2402 & 6.2543 & 29,581 \\
\hline Baseline number of exacerbations $=3$ & 23,028 & 23,440 & 4.8638 & 4.8975 & 12,259 \\
\hline $\begin{array}{l}\text { B) Incorporation of lung function } \\
\text { benefit }\end{array}$ & 22,816 & 23,170 & 5.4839 & 5.5249 & 8,617 \\
\hline C) Time on first line $=0.5$ years & 22,816 & 23,021 & 5.4839 & 5.4967 & 16,068 \\
\hline Time on first line $=2$ years & 22,816 & 23,597 & 5.4839 & 5.5309 & 16,628 \\
\hline D) Patients remain on first line & 22,816 & 26,602 & 5.4839 & 5.7111 & $|6,66|$ \\
\hline $\begin{array}{l}\text { E) Patients start in very severe } \\
\text { COPD }\end{array}$ & 26,444 & 26,883 & 4.4922 & 4.5279 & 12,310 \\
\hline $\begin{array}{l}\text { F) Treatment switch following } \\
\text { disease progression }\end{array}$ & 22,816 & 24,725 & 5.4839 & 5.5834 & 19,186 \\
\hline
\end{tabular}

Note: aRounded values.

Abbreviations: GBP, British pound; QALY, quality-adjusted life year; ICER, incremental cost-effectiveness ratio; ICS, inhaled corticosteroids; LABA, long-acting beta agonist; LAMA, long-acting muscarinic antagonist.

This study has employed standard best practice in health economic modeling and analysis to examine the cost-effectiveness of various treatment options in a fully incremental analysis.

The model structure was based on methods previously used in other COPD cost-effectiveness modeling studies, with regard to the definition of health states, method for calculation of disease progression, and modeling of mortality. ${ }^{19}$ However, to our knowledge, this study represents the first fully incremental analysis of commonly used COPD treatments which has been reported in the literature.
Two fully incremental analyses were performed for patients with severe COPD: one for patients able to receive ICS, and a second for patients who do not tolerate or decline ICS. In the analysis for those patients able to receive ICS, the cost-effectiveness frontier suggests to start patients on a first-line treatment with LABA or LAMA. For those who continue to exacerbate, LAMA + LABA/ICS presents a cost-effective option for a second-line treatment, followed by LAMA + LABA/ICS + roflumilast. The addition of roflumilast to LAMA + LABA/ICS is associated with an ICER of $£ 16,566$ per QALY gained.

Table 7 Results for scenario analyses, ICS-intolerant patients

\begin{tabular}{|c|c|c|c|c|c|}
\hline \multirow[t]{2}{*}{ Scenario } & \multicolumn{2}{|c|}{ Costs in GBPa } & \multicolumn{2}{|l|}{ QALYs $^{\mathbf{a}}$} & \multirow{2}{*}{$\begin{array}{l}\text { ICER (GBP per } \\
\text { QALY gained) } \\
\text { LAMA + LABA + } \\
\text { roflumilast versus } \\
\text { LAMA + LABA } \\
\end{array}$} \\
\hline & $\begin{array}{l}\text { LAMA + } \\
\text { LABA }\end{array}$ & $\begin{array}{l}\text { LAMA + LABA + } \\
\text { roflumilast }\end{array}$ & $\begin{array}{l}\text { LAMA + } \\
\text { LABA }\end{array}$ & $\begin{array}{l}\text { LAMA + LABA + } \\
\text { roflumilast }\end{array}$ & \\
\hline Base case & 21,814 & 22,222 & 5.1948 & 5.2244 & 13,764 \\
\hline A) Baseline number of exacerbations $=1$ & 21,296 & 21,710 & 6.0590 & 6.0761 & 24,186 \\
\hline Baseline number of exacerbations $=3$ & 22,128 & 22,532 & 4.5114 & 4.5505 & $|0,32|$ \\
\hline $\begin{array}{l}\text { B) Incorporation of lung function } \\
\text { benefit }\end{array}$ & 21,814 & 22,162 & 5.1948 & 5.2410 & 7,552 \\
\hline C) Time on first line $=0.5$ years & 21,814 & 22,016 & 5.1948 & 5.2100 & 13,336 \\
\hline Time on first line $=2$ years & $21,8 \mid 4$ & $22,58 \mathrm{I}$ & 5.1948 & 5.2503 & 13,826 \\
\hline D) Patients remain on first line & 21,814 & 25,408 & 5.1948 & 5.4563 & 13,744 \\
\hline $\begin{array}{l}\text { E) Patients start in very severe } \\
\text { COPD }\end{array}$ & 25,386 & 25,822 & 4.1721 & 4.2137 & 10,479 \\
\hline $\begin{array}{l}\text { F) Treatment switch following } \\
\text { disease progression }\end{array}$ & $21,8 \mid 4$ & 23,663 & 5.1948 & 5.3123 & 15,736 \\
\hline
\end{tabular}

Note: aRounded values.

Abbreviations: GBP, British pound; QALY, quality-adjusted life year; ICER, incremental cost-effectiveness ratio; LABA, long-acting beta agonist; LAMA, long-acting muscarinic antagonist. 
The analysis for patients who do not tolerate or decline ICS also identified the optimal place for roflumilast as being an add-on to the current standard of care (LAMA + LABA), where the addition of roflumilast to LAMA + LABA is associated with an ICER of $£ 13,764$ per QALY gained.

These suggested positions in the treatment pathway are in line with the algorithm recommended in NICE Guidelines CG101, and identify an optimal positioning for roflumilast as an add-on to the currently recommended standard of care. A range of sensitivity and scenario analyses were also performed on the comparisons, with the majority continuing to demonstrate the cost-effectiveness of the agent.

The strengths of this analysis include a model which was developed in line with the current best practice in the field of economic modeling of COPD treatments. Additional functionality allowed for a fully incremental analysis and treatment sequencing, which may be regarded as useful advances in this area. In addition, clinical parameters for the RRRs for exacerbations were derived from a recently published MTC, which assessed the breadth of available evidence.

Limitations of the analysis are principally related to the lack of published data, with no head-to-head clinical trial evidence being available for certain treatment regimens. Whilst the availability of the additive MTC $^{15}$ allowed these comparisons to be made, this does introduce uncertainty into the analysis, as illustrated by the OWSA and results for changes in the exacerbation rates. Furthermore, studies M2-124 and M2-125 were not powered to demonstrate the reduction of risk of severe exacerbations alone. ${ }^{9}$ The economic model estimated the number of severe exacerbations as a proportion of all exacerbations and assumed that exacerbation reduction translates into a proportional reduction of both community- and hospital-treated exacerbations. Very few studies reported the change in $\mathrm{FEV}_{1}$ between the treatments of interest, meaning that it was not possible to conduct an MTC for this endpoint. There is no robust analytical approach to estimate the one-off lung function benefit between therapies. The primary aim of COPD treatment is, however, the prevention of exacerbations, which was the key clinical input in this analysis. As many of the limitations of this study are related to the lack of available data, further research is required to improve the precision of any future analysis.

Despite these limitations, this is the most up-to-date costeffectiveness analysis of treatments for COPD, and the first to consider treatments within a fully incremental modeling framework. The results support the treatment pathway which is currently recommended in the NICE COPD Clinical
Guideline, and identifies the value of roflumilast as an add-on treatment to the current standards of care.

\section{Conclusion}

Overall these analyses suggest that the treatment algorithm recommended in UK clinical practice represents a costeffective approach for the management of COPD. The addition of roflumilast to the currently recommended standards of care is a clinical and cost-effective treatment strategy for patients with severe COPD who continue to exacerbate despite existing bronchodilator therapy.

\section{Acknowledgments and disclosure}

This study was sponsored by MSD Ltd, Hoddesdon, UK. All authors participated in the study design, data analysis, interpretation of the results, writing and reviewing of the manuscript and the decision to submit the manuscript for publication. Nadine Hertel, Robert W Kotchie, Yevgeniy Samyshkin, and Matthew Radford are employees of the IMS Consulting Group, which was commissioned by MSD Ltd to conduct this study. Samantha Humphreys and Kevin Jameson are employees of MSD Ltd and hold shares in the company.

\section{References}

1. Buist AS, Vollmer WM, McBurnie MA. Worldwide burden of COPD in high- and low-income countries. Part I. The burden of obstructive lung disease (BOLD) initiative. Int J Tuberc Lung Dis. 2008;12(7): 703-708.

2. Stats Wales. Welsh Assembly Government, [0024829] QOF disease registers; 2009-2010 [cited Apr 2011]. Available from: http://www. statswales.wales.gov.uk/TableViewer/tableView.aspx?ReportId=24813. Accessed November 3, 2011.

3. Health and Social Care Information Centre. National Prevalence, Quality and Outcomes Framework (QOF). Numbers on QOF disease registers and raw prevalence rates, England. Apr 2009-Mar 2010 [updated Jul 2010; cited Apr 2011]. Available from: http://www.ic.nhs.uk/webfiles/ QOF/2009-2010/Prevalence\%20tables/QOF0910_National_Prevalence. xls. Accessed November 3, 2011.

4. Russell R, Anzueto A, Weisman I. Optimizing management of chronic obstructive pulmonary disease in the upcoming decade. Int J Chron Obstruct Pulmon Dis. 2011;6:47-61.

5. GOLD Strategy Group. Global Strategy for the Diagnosis, Management and Prevention of COPD, Global Initiative for Chronic Obstructive Lung Disease (GOLD) 2010 [updated 2010; cited Apr 2011]. Available from: http://www.goldcopd.org. Accessed November 3, 2011.

6. National Institute for Health and Clinical Excellence. NICE Clinical Guideline 101: Chronic obstructive pulmonary disease: Management of chronic obstructive pulmonary disease in adults in primary and secondary care [updated Jun 2010; cited Apr 2011]. Available from: http://guidance. nice.org.uk/CG101. Accessed November 3, 2011.

7. European Medicines Agency. Daxas: Summary of product characteristics [updated May 3, 2011; cited Apr 2011]. Available from: http://www.ema. europa.eu/docs/en_GB/document_library/EPAR_-_Product_Information/ human/001179/WC500095209.pdf. Accessed November 3, 2011. 
8. Hurst JR, Vestbo J, Anzueto A, et al. Susceptibility to exacerbation in chronic obstructive pulmonary disease. N Engl J Med. 2010;363(12): 1128-1138.

9. Calverley PM, Rabe KF, Goehring UM, Kristiansen S, Fabbri LM, Martinez FJ. Roflumilast in symptomatic chronic obstructive pulmonary disease: two randomised clinical trials. Lancet. 2009;374(9691): 685-694.

10. Bateman ED, Rabe KF, Calverley PM, et al. Roflumilast with longacting \{beta\}2-agonists for COPD: influence of exacerbation history. Eur Respir J. 2011;38(3):553-560.

11. Food and Drug Administration. Department of Health and Human Services, United States [cited Apr 2011]. Available from: http://www. fda.gov/default.htm. Accessed November 3, 2011.

12. The European Medicines Agency. [cited Apr 2011]. Available from: http://www.ema.europa.eu. Accessed November 3, 2011.

13. Briggs A, Sculpher M. An introduction to Markov modelling for economic evaluation. Pharmacoeconomics. 1998;13(4):397-409.

14. Kotchie RW, Samyshkin Y, Zammit D, Humphreys S, Jameson K. The cost-effectiveness of Roflumilast in the management of severe COPD in the UK setting. International society for Pharmacoeconomics and Outcomes Research (ISPOR ), 16th Annual International Meeting, May 21-25, 2011, Baltimore, MD, USA. Poster No: PRS18.

15. Mills EJ, Druyts E, Ghement I, Puhan MA. Pharmacotherapies for chronic obstructive pulmonary disease: a multiple treatment comparison meta-analysis. Clin Epidemiol. 2011;3:107-129.

16. Crapo RO, Morris AH, Gardner RM. Reference spirometric values using techniques and equipment that meet ATS recommendations. Am Rev Respir Dis. 1981;123(6):659-664.

17. Royal College of Physicians, British Thoracic Society, British Lung Foundation. Report of the National Chronic Obstructive Pulmonary Disease Audit 2008: Clinical audit of COPD exacerbations admitted to acute NHS units across the UK 2008 [cited Apr 2011]. Available from: http:/www.brit-thoracic.org.uk/Portals/0/Clinical\%20Information/COPD/ NCROP/NCROPClinicalAudit.pdf. Accessed November 3, 2011.

18. National Institute for Health and Clinical Excellence. NICE: Guide to the methods of technology appraisal 2008. [cited Apr 2011]. Available from: http://www.nice.org.uk/aboutnice/howwework/devnicetech/ technologyappraisalprocessguides/guidetothemethodsoftechnology appraisal.jsp. Accessed November 3, 2011.
19. Spencer M. Development of an economic model to assess the cost effectiveness of treatment interventions for chronic obstructive pulmonary disease. Pharmacoeconomics. 2005;23(6):619-637.

20. Scanlon PD, Connett JE, Waller LA, Altose MD, Bailey WC, Buist AS. Smoking cessation and lung function in mild-to-moderate chronic obstructive pulmonary disease. The Lung Health Study. Am J Respir Crit Care Med. 2000;161(2 Pt 1):381-390.

21. Rutten-van Molken MPMH, Hoogendoorn M, Lamers LM. Holistic preferences for 1-year health profiles describing fluctuations in health: The case of chronic obstructive pulmonary disease. Pharmacoeconomics. 2009;27(6):465-477.

22. Joint Formulary Committee British Medical Association and Royal Pharmaceutical Society. British National Formulary 61. 2011 [cited Apr 2011]. Available from: http://bnf.org/bnf/index.htm. Accessed November 3, 2011.

23. Department of Health, UK. NHS reference costs 2009-2010 [updated January 13, 2011; cited Apr 2011]. Available from: http://www. dh.gov.uk/en/Publicationsandstatistics/Publications/Publications PolicyAndGuidance/DH_123459. Accessed November 3, 2011.

24. Oostenbrink JB, Rutten-van M, Monz BU, Fitzgerald JM. Probabilistic Markov model to assess the cost-effectiveness of bronchodilator therapy in COPD patients in different countries. Value Health. 2005;8(1):32-46.

25. Personal Social Services Research Unit, UK. Unit Costs of Health and Social Care 2010 [cited Apr 2011]. Available from: http://www.pssru. ac.uk/pdf/uc/uc2010/uc2010.pdf. Accessed November 3, 2011.

26. Drummond MF, Sculpher MJ, Torrance GW, O’Brien BJ, Stoddart GL. Cost-effectiveness analysis. In: Drummond MF, Sculpher MJ, Torrance GW, O'Brien BJ, Stoddart GL, editors. Methods for the Economic Evaluation of Health Care Programmes. 3rd edition. Oxford, UK: Oxford University Press; 2005:103-136.

27. Personal Social Services Research Unit, UK [www.pssru.ac.uk]. Unit Costs of Health and Social Care 2010. Hospital and Community Health Services (HCHS) Pay and Price Index. [cited April 2011] Available from: http://www.pssru.ac.uk/pdf/uc/uc2010/uc2010_inflationindices. pdf. Accessed November 3, 2011. 


\section{Appendix}

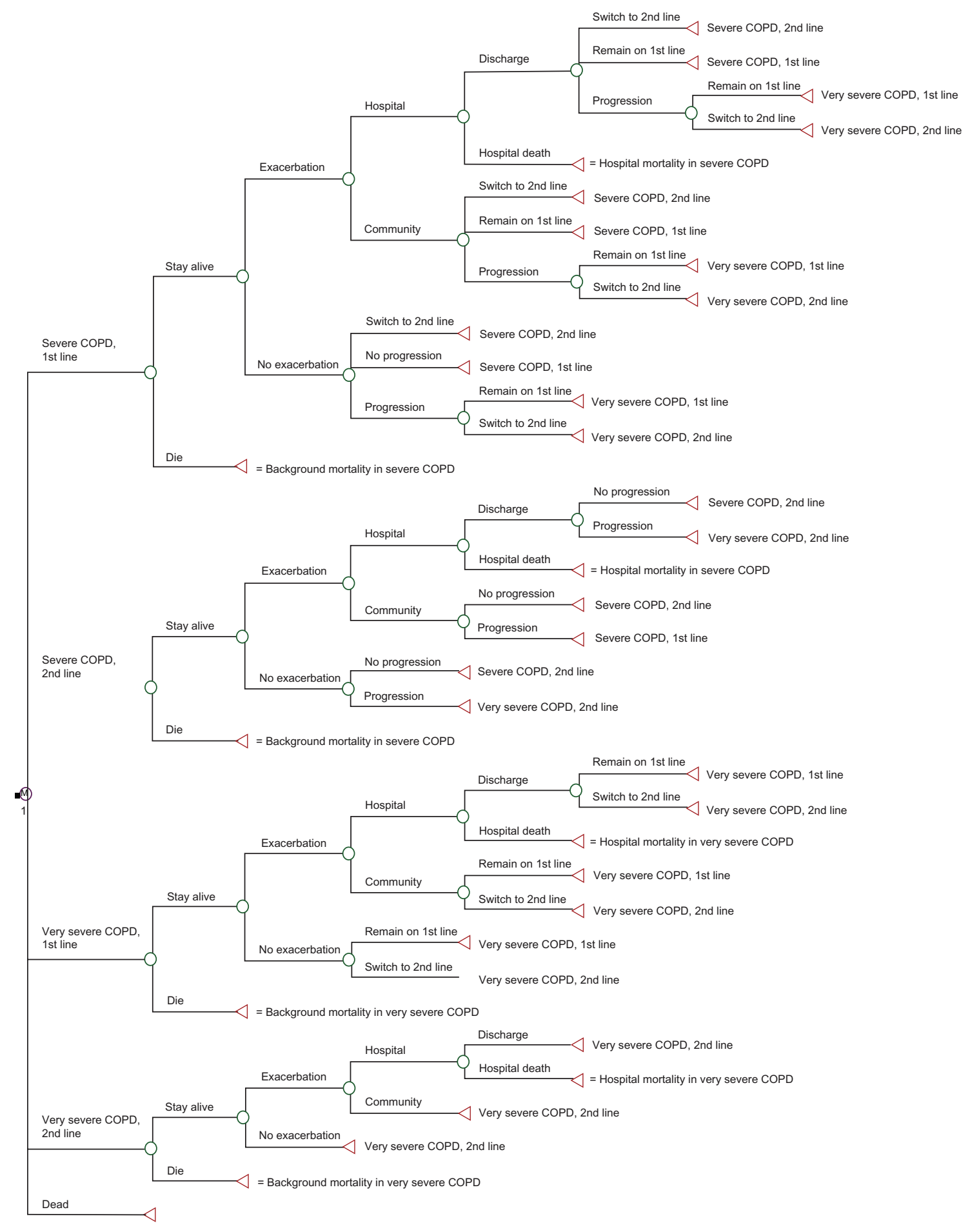

Figure AI Detailed model scheme. 
Table Al Outpatient costs for COPD drugs, maintenance of severe and very severe COPD, and community-treated exacerbation

\begin{tabular}{|c|c|c|c|c|}
\hline Cost category & Unit cost in GBP & Resource use & $\begin{array}{l}\text { Costs } \\
\text { in GBP }\end{array}$ & Calculation/reference \\
\hline \multicolumn{5}{|l|}{ COPD drugs } \\
\hline $\begin{array}{l}\text { Roflumilast } \\
\text { (Daxas }^{\circledR} \\
\text { Nycomed, Zurich, } \\
\text { Switzerland }\end{array}$ & 30-day pack $=£ 37.71$ & & 38.23 & $\begin{array}{l}\text { Costs per model cycle. Based on the cost } \\
\text { of } 30 \text {-day pack of } t 37.71 \text {, adjusted to the } \\
\text { average days per month of } 365 / 12 \text {. Unit } \\
\text { cost source:22 }\end{array}$ \\
\hline $\begin{array}{l}\text { LABA } \\
\text { Salmeterol } \\
\text { (Serevent }^{\circledR} \\
\text { Evohaler }^{\circledR}, \text { Accuhaler }^{\circledR} \\
\text { and Diskhaler } \\
\text { GlaxoSmithKline, } \\
\text { Brentford, UK) }\end{array}$ & $\begin{array}{l}\text { Evohaler: } 25 \text { mcg per dose, } \\
\text { I20-dose unit = } £ 29.26 \text {; } \\
\text { Accuhaler: } 50 \text { mcg per dose, } \\
\text { 60-dose unit = } £ 29.26 \text {; } \\
\text { Diskhaler: } 50 \text { mcg per disk, } \\
\text { 60-disk pack, with device = } \\
£ 35.79 \text {; } 60 \text {-disk refill pack = } \\
£ 35.15\end{array}$ & 50 mcg twice daily & 29.67 & $\begin{array}{l}\text { Costs per model cycle: }(£ 29.26 / 30) *(365 / I 2) \text {. } \\
\text { Calculated cost for LABA assumes all items } \\
\text { are prescribed as the Accuhaler or Evohaler, } \\
\text { which are associated with a lower daily } \\
\text { treatment cost than the Diskhaler (or refills). } \\
\text { Unit cost source: }{ }^{22}\end{array}$ \\
\hline $\begin{array}{l}\text { LAMA } \\
\text { Tiotropium } \\
\left(\text { Spiriva }{ }^{\circledR}, \text { Boehringer }\right. \\
\text { Ingelheim, Ingelheim, } \\
\text { Germany) }\end{array}$ & $\begin{array}{l}\text { 30-cap refill pack ( } 18 \mathrm{mcg} \\
\text { per cap) }=€ 31.89 ; 30 \text {-cap } \\
\text { pack }(18 \mathrm{mcg} \text { per cap) with } \\
\text { HandiHaler device }=£ 34.87\end{array}$ & I8 mcg once daily & 32.33 & $\begin{array}{l}\text { Costs per model cycle: }(£ 3 I .89 / 30) *(365 / 12) \text {. } \\
\text { Calculated cost for LAMA assumes all items } \\
\text { are prescribed as refill packs, } \\
\text { which are associated with a lower daily } \\
\text { treatment cost than when combined } \\
\text { with the HandiHaler device. Unit } \\
\text { cost source:22 }\end{array}$ \\
\hline $\begin{array}{l}\text { LABA/ICS } \\
\text { Salmeterol/ } \\
\text { fluticasone } \\
\text { (Seretide }{ }^{\circledR} 500 \text { Accuhaler } \\
\text { GlaxoSmithKline) }\end{array}$ & $\begin{array}{l}50 \mathrm{mcg} \text { salmeterol } \\
\text { (as xinafoate) }+500 \mathrm{mcg} \\
\text { fluticasone per puff, } 60 \text {-dose } \\
\text { Accuhaler }=£ 40.92\end{array}$ & $\begin{array}{l}\text { I dose of Seretide } \\
500, \text { twice daily }\end{array}$ & 41.49 & $\begin{array}{l}\text { Costs per model cycle: }(£ 40.92 / 30) *(365 / I 2) \text {. } \\
\text { Unit cost source: }{ }^{22}\end{array}$ \\
\hline \multicolumn{5}{|c|}{ Maintenance, severe COPD } \\
\hline $\begin{array}{l}\text { Outpatient visit } \\
\text { respiratory physician }\end{array}$ & 131.12 & Twice a year & 21.85 & $\begin{array}{l}\text { National schedule of reference costs } 2009 / 10 .{ }^{23} \\
\text { Consultant-led face to face attendance/ } \\
\text { respiratory medicine. Service code } 340\end{array}$ \\
\hline Spirometry & 49.98 & Twice a year & 8.33 & $\begin{array}{l}\text { National schedule of reference costs } 2009 / 10 .^{23} \\
\text { NHS Trusts and PCTs combined direct } \\
\text { access: diagnostic services/spirometry test } \\
\text { and bronchodilator response test. DA07 }\end{array}$ \\
\hline Influenza vaccination & 4.15 & $\begin{array}{l}75 \% \text { of patients } \\
\text { annual vaccination }\end{array}$ & 0.26 & $\begin{array}{l}\text { Injection, suspension of propiolactone- } \\
\text { inactivated influenza virus (surface antigen, } \\
\text { grown in fertilized hens' eggs), net price } \\
0.5-\mathrm{mL} \text { prefilled syringe }=£ 4.15 \text {. Unit } \\
\text { cost source:22 }\end{array}$ \\
\hline Oxygen therapy & 14.70 & 1.22 days & 17.89 & $\begin{array}{l}\text { Cost per day of } 12.64 \text { Euro has been inflated } \\
\text { from } 200 \mathrm{I} \text { to } 2010 \text { values using the Hospital } \\
\text { and Community Health Services (HCHS) } \\
\text { pay and price index from the PSSRU }{ }^{27} \text { and } \\
\text { converted to GBP }\end{array}$ \\
\hline Average monthly cost & & & 48.33 & $\begin{array}{l}\text { Estimates of resource use are based on } \\
\text { published literature. }{ }^{24} \text { This study was } \\
\text { conducted in The Netherlands and Canada, } \\
\text { and resource utilization was assumed to be } \\
\text { applicable to the UK }\end{array}$ \\
\hline \multicolumn{5}{|c|}{ Maintenance, very severe COPD } \\
\hline $\begin{array}{l}\text { Outpatient visit } \\
\text { respiratory physician }\end{array}$ & 131.12 & Four times a year & 43.71 & $\begin{array}{l}\text { National schedule of reference costs } 2009 / 10 .{ }^{23} \\
\text { Consultant-led face to face attendance/ } \\
\text { respiratory medicine. Service code } 340\end{array}$ \\
\hline Spirometry & 49.98 & Four times a year & 16.66 & $\begin{array}{l}\text { National schedule of reference costs } 2009 / 10 .^{23} \\
\text { NHS Trusts and PCTs combined direct } \\
\text { access: diagnostic services/spirometry test } \\
\text { and bronchodilator response test. DA07 }\end{array}$ \\
\hline
\end{tabular}


Table A I (Continued)

\begin{tabular}{|c|c|c|c|c|}
\hline Cost category & Unit cost in GBP & Resource use & $\begin{array}{l}\text { Costs } \\
\text { in GBP }\end{array}$ & Calculation/reference \\
\hline Influenza vaccination & 4.15 & $\begin{array}{l}75 \% \text { of patients } \\
\text { annual vaccination }\end{array}$ & 0.26 & $\begin{array}{l}\text { Injection, suspension of propiolactone- } \\
\text { inactivated influenza virus (surface antigen, } \\
\text { grown in fertilized hens' eggs), net price } \\
0.5-\mathrm{mL} \text { prefilled syringe }=£ 4.15 \text {. Unit } \\
\text { cost source: }{ }^{22}\end{array}$ \\
\hline Oxygen therapy & 14.70 & 6.08 days & 89.43 & $\begin{array}{l}\text { Cost per day of } 12.64 \text { Euro has been inflated } \\
\text { from } 200 \mathrm{I} \text { to } 2010 \text { values using } \\
\text { the Hospital and Community Health Services } \\
\text { (HCHS) pay and price index from the } \\
\text { PSSRU }^{27} \text { and converted to GBP. }\end{array}$ \\
\hline Average monthly cost & & & 150.05 & $\begin{array}{l}\text { Estimates of resource use are based on } \\
\text { published literature. }{ }^{24} \text { This study was } \\
\text { conducted in the Netherlands and Canada, } \\
\text { and resource utilization was assumed to be } \\
\text { applicable to the UK. }\end{array}$ \\
\hline \multicolumn{5}{|c|}{ Community-treated exacerbation } \\
\hline $\begin{array}{l}\text { GP (consultation } \\
\text { lasting II.7 minutes) }\end{array}$ & 36.00 & I (Proportion: 2/3) & 24.00 & $\begin{array}{l}\text { Assumption: } 2 / 3 \text { of patients are treated by } \\
\text { GP (unit cost source: }{ }^{25} \text { ) and I/3 of patients } \\
\text { treated in A \& E, ie Accident \& Emergency } \\
\text { services: not leading to hospital admission. }\end{array}$ \\
\hline$A \& E$ (no admission) & 126.78 & I (Proportion: I/3) & 42.26 & Currency Code: VB06Z (unit cost source: ${ }^{23}$ ). \\
\hline Prednisolone $30 \mathrm{mg}$ & 0.57 & $\begin{array}{l}7 \text { days } \\
\text { (Proportion: } 1 / 2 \text { ) }\end{array}$ & 2.00 & $\begin{array}{l}\text { I } \times 25 \mathrm{mg} \text { tablet and I } \times 5 \mathrm{mg} \text { tablet; } \\
\text { Assumption: } 50 \% \text { have treatment for } 7 \text { days } \\
\text { and } 50 \% \text { have treatment for } 14 \text { days. Unit } \\
\text { cost source: } 22\end{array}$ \\
\hline Prednisolone $30 \mathrm{mg}$ & 0.57 & $\begin{array}{l}\text { I4 days } \\
\text { (Proportion: I/2) }\end{array}$ & 4.01 & \\
\hline Co-amoxiclav 500 mg & 0.26 & $\begin{array}{l}3 \text { days } \\
\text { (Proportion: } 1 / 2 \text { ) }\end{array}$ & 0.39 & $\begin{array}{l}\text { Resource use source: }{ }^{5} \text {. Assumption: } 50 \% \\
\text { have treatment for } 3 \text { days and } 50 \% \text { have } \\
\text { treatment for } 7 \text { days. Unit cost source: } 22\end{array}$ \\
\hline Co-amoxiclav 500 mg & 0.26 & $\begin{array}{l}7 \text { days } \\
\text { (Proportion: I/2) }\end{array}$ & 0.91 & \\
\hline Average cost of a comr & -treated exacerbation & & 73.56 & \\
\hline
\end{tabular}

Abbreviations: GBP, British pound; QALY, quality-adjusted life year; ICS, inhaled corticosteroids; LABA, long-acting beta agonist; LAMA, long-acting muscarinic antagonist; GP, general practitioner. 
Table A2 Inpatient cost of a hospital-treated exacerbation

\begin{tabular}{|c|c|c|c|c|c|}
\hline \multirow{3}{*}{$\begin{array}{l}\text { HRG } \\
\text { code }\end{array}$} & \multirow[t]{3}{*}{ HRG description } & \multicolumn{4}{|c|}{ NHS trusts non-elective inpatient HRG data } \\
\hline & & \multicolumn{2}{|l|}{ Long stay } & \multicolumn{2}{|c|}{ Short stay } \\
\hline & & Activity & $\begin{array}{l}\text { National average } \\
\text { unit cost in GBP }\end{array}$ & Activity & $\begin{array}{l}\text { National average } \\
\text { unit cost in GBP }\end{array}$ \\
\hline $\mathrm{DZ2IA}$ & COPD or bronchitis with length of stay $\leq \mathrm{I}$ day discharged home & 8,202 & 747 & 61,819 & 391 \\
\hline DZ2IB & COPD or bronchitis with Intubation with major CC & 101 & 2,306 & 24 & 577 \\
\hline DZ2IC & COPD or bronchitis with Intubation with CC & 19 & $2,|7|$ & 8 & 448 \\
\hline DZ2ID & COPD or bronchitis with Intubation without CC & 4 & $\mathrm{I}, 725$ & I & 320 \\
\hline DZ2IE & COPD or bronchitis with NIV without intubation with major CC & 3,360 & 2,280 & 362 & 490 \\
\hline DZ2IF & COPD or bronchitis with NIV without intubation with CC & 993 & 2,099 & 83 & 525 \\
\hline DZ2IG & COPD or bronchitis with NIV without intubation without CC & 218 & $\mathrm{I}, 724$ & 19 & 390 \\
\hline $\mathrm{DZ2IH}$ & COPD or bronchitis without NIV without intubation with major CC & 34,530 & 2,029 & 4,521 & 424 \\
\hline DZ2IJ & COPD or bronchitis without NIV without intubation with CC & 46,986 & 1,643 & 4,780 & 387 \\
\hline \multirow[t]{5}{*}{ DZ2IK } & COPD or bronchitis without NIV without intubation without CC & $\mid \mathrm{I}, 72 \mathrm{I}$ & 1,279 & $\mathrm{I}, 276$ & 385 \\
\hline & & $\begin{array}{l}\text { Weighted } \\
\text { average }\end{array}$ & $1,684.15$ & & 393.32 \\
\hline & & \multicolumn{3}{|c|}{ Weighted average estimates per hospitalization } & $\mathrm{I}, 158.57$ \\
\hline & & \multicolumn{3}{|c|}{ Weighted cost of ambulance transportation } & 188.06 \\
\hline & & \multicolumn{3}{|c|}{$\begin{array}{l}\text { Average cost of a hospital-treated } \\
\text { exacerbation }\end{array}$} & $1,346.63$ \\
\hline
\end{tabular}

Notes: aCalculated according to the formula: [(sum_activity units $\times$ sum_national average unit cost) $\left.{ }_{\text {LONG STAY }}+(\text { sum_activity units } \times \text { sum_national average unit cost })_{\text {SHORT STAY }}\right] /$ [(sum_activity units) LONG STAY $_{\text {(sum_activity units) }}+$ SHORT STAY $]$. Source: ${ }^{23}$; ${ }^{b}$ the cost of ambulance transportation was estimated at $£ 208.95$ based on the National Schedule of Reference Costs Year: '2009/10' - NHS trusts paramedic services: category B/Amber, service code PS06B (06 breathing problems; breathing difficulty). It was assumed that $90 \%$ of patients would be delivered to hospital by ambulance. ${ }^{23}$

Abbreviations: NHS, National Health Service; HRG, Healthcare Resource Group; COPD, chronic obstructive pulmonary disease; NIV, Non-invasive ventilation; GBP, British pound; CC, complications and co-morbidities.

\section{Publish your work in this journal}

The International Journal of COPD is an international, peer-reviewed journal of therapeutics and pharmacology focusing on concise rapid reporting of clinical studies and reviews in COPD. Special focus is given to the pathophysiological processes underlying the disease, intervention programs, patient focused education, and self management protocols.

\section{Dovepress}

This journal is indexed on PubMed Central, MedLine and CAS. The manuscript management system is completely online and includes a very quick and fair peer-review system, which is all easy to use. Visit http://www.dovepress.com/testimonials.php to read real quotes from published authors. 